\title{
O engajamento on-line do consumidor em mídias sociais de serviços turísticos: uma análise comparativa entre as companhias aéreas brasileiras a partir de suas fanpages
}

\author{
Jacilene Barbosa de Arruda* André Falcão Durão** \\ Alexandre César Batista da Silva*** \\ Carla Borba da Mota Silveira***** \\ Universidade Federal de Pernambuco (Brasil)
}

\begin{abstract}
Resumo: Esta pesquisa teve por objetivo analisar de que forma se dá o engajamento dos consumidores com as companhias aéreas em suas respectivas fanpages. Como suporte teórico, utilizou TICs e mídias sociais, serviços turísticos e o engajamento do consumidor. Trata-se de uma investigação exploratório-descritiva, com abordagem qualitativa e o estudo de casos múltiplos como estratégia de pesquisa. Os resultados mostraram que as fanpages das companhias aéreas precisam de ajustes no que diz respeito à frequência de postagem, postagens de vídeo, redução do tamanho das postagens escritas e resposta ao usuário.
\end{abstract}

Palavras-chave: Companhias aéreas; Mídias sociais; Facebook; Engajamento do consumidor.

On-line consumer engagement on tourism services' socialmedia: a comparative analysis between brazilian air companies' fanpages

Abstract: The overall objective of the research was to analyse how air companies engage with their clients in their respective fan_pages of their regions. The methodology used was critical discourse analysis of air companies fan-pages. This is exploratory-descriptive research, with a qualitative approach and the study of multiple cases as a research strategy. The results show that airline fan pages need greater updating, video posts, longer postings, and greater reponse to their users.

Keywords: Airlines; Social media; Facebook; Consumer engagement.

\section{Introdução}

A Web 2.0 é caracterizada por não ser mais apenas um ambiente estático ou de leitura, como na Web 1.0, pois permite que sejam desenvolvidas respostas mais inteligentes aos usuários, por meio do grande número de compartilhamentos e interações que ocorrem nesse ambiente. Lévy e Lemos (2010) denominaram essa nova onda de computação social, afirmando que nela a criação e organização de conteúdo são feitos pelos próprios utilizadores.

A então chamada Web 2.0, caracterizada por O'Reilly (2007) foi uma nova visão de internet, onde os usuários passaram a ter uma interação maior. mídias sociais como o Facebook, o Instagram e o Twitter são criações deste período.

Nesse contexto de Web 2.0 ou participativa, o Facebook se destaca como ferramenta que agrega os usuários e propicia, constantemente, novas interações por meio de atualizações, o que direciona comportamentos, dadas as regras de utilização, sempre buscando aprimorar a vivência experienciada na rede, tornando-a mais eficiente e de fácil utilização (Oliveira et al., 2017).

\footnotetext{
* Universidade Federal de Pernambuco (Brasil); E-mail: jacilenebarbosa2013.2@gmail.com; https://orcid.org/0000-0002-7190-4598

* Universidade Federal de Pernambuco (Brasil); E-mail: afdurao@gmail.com; https://orcid.org/0000-0001-7505-7173

*** Universidade Federal de Pernambuco (Brasil); E-mail: acbspe@uol.com.br; https://orcid.org/0000-0001-7411-8579

*** Universidade Federal de Pernambuco (Brasil); E-mail: carlaborbasilvera@gmail.com; https://orcid.org/0000-0003-0540-8577
} 
Porém, essa lógica não se restringe apenas à interação entre pessoas, mas também entre empresas e entre empresas e consumidores. Assim, no contexto corporativo, faz-se necessário compreender quem é o cliente que está por trás da linha virtual, qual o seu comportamento diante de ações realizadas dentro e fora da realidade virtual e que tipo de ferramentas são fundamentais para que as empresas consigam atingir e atender aos anseios desses consumidores. E, no caso desta pesquisa, que tem por foco as companhias aéreas, para que estas consigam atingir suas metas de satisfação do cliente por meio de atividades on-line ligadas diretamente às atividades que ocorrem simultaneamente no "mundo real".

Com a internet e suas múltiplas possibilidades de comunicação e interação, empresas de serviços turísticos modificaram fortemente a forma de relacionamento com seus consumidores. As empresas prestadoras de serviços de transporte aéreo, em um contexto da atividade turística, também fazem parte deste conjunto de organizações que tiveram que readequar suas formas de lidar com clientes/ turistas.

Segundo dados do Global Digital Report da agência We Are Social (2019), o número de pessoas com internet no Brasil é de 149 milhões ( $70 \%$ da população). Neste período houve o aumento de 7,2\% dos usuários nas mídias sociais. Os dados também evidenciam que o Brasil está em terceiro no ranking de países que os usuários passam mais tempo na internet, são mais de 9 horas navegando e mais de 3 horas diárias gastas nas mídias sociais.

Ainda segundo dados da Agência We Are Social (2019), os brasileiros passam em média 13min55s na mídia social Facebook, diariamente, sendo uma das mais utilizadas, com destaque para os vídeos que são postados na rede, pois apresentam um percentual de engajamento de $6,83 \%$ dos seguidores das páginas, seguido pelos links de compartilhamento, que representam $6,46 \%$ (contra a média de $5,23 \%$ e $3,90 \%$ dos demais países) e em terceiro lugar estão as fotos, com 5,84\% no percentual de engajamento.

O engajamento, que pode ser entendido como a forma de comprometimento de uma pessoa com alguma coisa por meio da indução, do incitamento e do convencimento, é utilizado para mensurar o desempenho do Facebook e de outras mídias sociais como ferramenta de divulgação (Silva et al., 2013).

De acordo com Fernandes (2019), dos cinco apps (aplicativos) mais baixados no Mundo, quatro são de interação social, são eles: Facebook Messenger, Facebook, WhatsApp e Instagram respectivamente. As possibilidades de uso destas ferramentas por empresas e consumidores são extremamente relevantes, assim como uma pesquisa sobre sua utilização por prestadores de serviços aéreos.

Dados do Balanço de 2017 do Ministério dos Transportes, Portos e Aviação Civil (2018) brasileiro, indicam que:

A movimentação de passageiros (embarque e desembarque) nos aeroportos brasileiros registrou aumento em 10 dos 12 meses do ano de 2017. No comparativo com 2016, o aumento registrado foi de $2,33 \%$. Os 20 principais aeroportos, responsáveis por $90 \%$ da movimentação de passageiros, movimentaram 205,91 milhões de viajantes contra 201,22 milhões no ano anterior(parág. 1).

Ainda de acordo com o ministério dos transportes, portos e aviação civil (2017), a movimentação no mercado doméstico teve um crescimento de $2,12 \%$ no ano. Já as viagens internacionais registraram alta de $4,20 \%$, o que se deve, segundo o ministro da pasta, ao crescimento positivo das expectativas econômicas, que tendem a evoluir e apresentar taxas de crescimento acima de $4 \%$ ao ano, a partir de 2019 (Ministério dos Transportes, Portos e Aviação Civil, 2018).

Tendo em vista a importância desse contexto, as empresas prestadoras de serviços de transportes aéreos não podem ficar alheias a essa evolução tecnológica e devem utilizar suas mídias sociais on-line como ferramentas essenciais de comunicação e venda no mercado, integrando o seu mix de marketing. É importante que essas práticas estejam em consonância com o perfil do consumidor atual, cada vez mais exigente, ávido por informações e por experiências prazerosas no ambiente virtual.

Dado o cenário apresentado, esta pesquisa tem por foco de análise o Facebook das quatro companhias aéreas com maior representatividade no mercado brasileiro: LATAM, GOL, AZUL e AVIANCA (Agência Nacional de Aviação Civil [ANAC], 2018).

A LATAM tem o maior número de seguidores (11.363.540) na sua página do Facebook. Logo em seguida está a Azul Linhas Aéreas, com o total de 4.152.280 seguidores em sua Fanpage. A GOL alcançou 1 milhão de fãs 2 anos depois de sua chegada nesta rede social e atualmente conta com 3.521.685 seguidores em sua página. Já a AVIANCA é a que possui a menor quantidade de seguidores (1.653.661). 
Assim, esta pesquisa estabelece um comparativo entre essas quatro companhias aéreas, destacando a quantidade de seguidores em suas páginas no Facebook e seus respectivos percentuais de engajamento (que serão discutidos no decorrer deste trabalho), além de apresentar uma tipologia de postagens, onde alguns tipos de posts geram mais engajamento que outros.

Tomando por base a premissa de que as companhias aéreas LATAM, GOL, AZUL e AVIANCA, são as empresas aéreas que investem em mídias sociais na atualidade, sendo esta uma das razões que motivou o desenvolvimento desta pesquisa, emerge o questionamento norteador do estudo:de que forma se dá o engajamento dos consumidores das companhias aéreas brasileiras em suas respectivas Fanpages?

Para o desenvolvimento dos resultados da pesquisa, foram utilizados como metodologia, a ferramenta LikeAlyzer e a observação on-line não participante. As empresas aéreas LATAM, GOL e AZUL oscilam no engajamento on-line, enquanto a empresa aérea AVIANCA, segundo resultados da pesquisa, apresenta dificuldades nesta rede social (Facebook). Os resultados, portanto, mostraram que as fanpages das companhias aéreas precisam de ajustes no que diz respeito à frequência de postagem, postagens de vídeo, redução do tamanho das postagens escritas e resposta ao usuário.

\section{Revisão de literatura}

\subsection{Redes Sociais e Serviços Turísticos}

Segundo a OMT (2013), os consumidores estão tendo mais acesso às informações sobre produtos e serviços oferecidos pelas organizações, com mais facilidade e rapidez. Por isso estão se tornando cada vez mais exigentes e atentos às práticas que são utilizadas pelas empresas para convencê-los de que seus produtos e serviços atendem melhor às suas necessidades.

De acordo com pesquisa Global (2018) da PricewaterhouseCoopers sobre o comportamento do consumidor brasileiro e suas compras on-line na internet, cerca de $46 \%$ dos entrevistados citaram que as mídias sociais são a fonte de inspiração mais influente na decisão de consumo.

Dentre as vantagens da internet para as organizações, Ogden e Criscitelli (2007) destaca o baixo custo, a agilidade, as formas múltiplas de mensuração, o marketing personalizado, a possibilidade de obter informações sobre os clientes por meio de tecnologias existentes e, assim, poder direcionar seus serviços e a distribuição irrestrita da informação.

Ainda de acordo com Ogden e Criscitelli (2007), para que as mídias sociais de uma empresa sejam utilizadas como ferramentas eficientes de e-marketing, o planejador, além de ter uma compreensão básica de internet, deve elaborar o plano de marketing digital objetivando fortalecer três pilares que sustentam a base do negócio digital: a comunicação, o relacionamento e as vendas.

Para Reino (2012), as empresas precisam executar práticas que possibilitem o estreitamento das relações com os clientes por meio das mídias sociais, já que são canais amplamente utilizados na atualidade, que propiciam interação e a troca de informações de maneira rápida, prática e eficiente. Além disso, para Lacerda (2018), as mudanças na forma da busca por informação no ambiente virtual impactaram drasticamente o processo de decisão e compra do consumidor, evidenciando-se, assim, a importância de planejar bem as ações corporativas de mídias nas mídias sociais.

As mídias sociais, juntamente com outras práticas on-line como sites, blogs, vlogs, entre outros, fazem parte de um conjunto conhecido como mídias sociais, que integram perfis de usuários e comunidades geradas pelos próprios consumidores ou pelas empresas, de maneira que contribuam com uma aproximação e a sensação de estarem mais íntimos com todos que delas fazem parte. Para Yadav e Pavlou (2014), esta interação é de constante mudança, já que as transformações na comunicação não são estáveis. A cada momento, na atualidade, surge uma nova forma de interagir e gerar comunicação, como novos recursos (aplicativos, novas mídias e programas) e assim proporcionar ainda mais experiências e relacionamentos empresa-cliente.

Com enfoque nas mídias sociais, Baldan, Eras, Fedichina e Gozzi (2011) indicam que "as mídias sociais podem contribuir para o fortalecimento da relação com clientes, o que tem feito com que as organizações tenham iniciado um processo de relacionamento e divulgação por meio das novas mídias” (p. 1).

O processo de comunicação e informacão, por meio da internet e mídias sociais, está se tornando um elemento fundamental na competitividade das entidades e destinos turísticos, bem como nas relações que definem o sistema turístico (Mihajlović, 2012).

O rápido desenvolvimento das tecnologias de informação, particularmente a internet, modificou drasticamente o contexto socioeconômico da atividade turística e são esperadas outras mudanças ao 
longo do tempo. Desde sua introdução, a internet se tornou o principal canal de distribuição de negócios relacionados ao turismo, estabelecendo um elo entre a comunicação e as vendas aos consumidores (Jang, 2004; Menezes \& Cunha, 2013), abrangendo praticamente todos os setores ligados ao trade turístico, onde pode-se destacar o de transporte aéreo.

O setor aéreo possui uma intensa competitividade, por isso as empresas aéreas precisam conhecer as necessidades, expectativas e prioridades dos seus clientes para aumentar a vantagem competitiva (Basfirinci \& Mitra, 2015).

Para Hussain, Nasser e Hussain (2015) em função de um setor aéreo competitivo, a satisfação do cliente não é suficiente, é preciso ultrapassar suas expectativas criando relacionamentos de longo prazo, de fidelidade à marca.

Uma das ferramentas que pode ser utilizada para fomentar relações de longo prazo entre clientes e empresas, promovendo a fidelização, são as mídias sociais e a capacidade das empresas em engajar seus consumidores no ambiente on-line corporativo e, consequentemente, obter resultados positivos duradouros, como evidenciado a seguir.

\subsection{Engajamento do Consumidor on-line}

A web, por meio das mídias sociais, permite que os atores das redes sociais participem, colaborem, promovam, compartilhem, opinem e discutam conteúdo e informação de maneira bilateral (Primo, 2007; Suzart \& Dias Filho, 2009; Terra, 2010), o que inclui interagir com as marcas que agora passam a figurar no ambiente on-line por meio das mídias sociais.

A internet permite que os consumidores virtuais pesquisem, comparem preços e declarem sua opinião sobre o produto, marca ou empresa (Cavallini, 2008). Para Santiago (2009, p. 43), os usuários também querem estar inseridos e conectados na web 2.0, pois buscam a socialização.

A ideia de se engajar com uma comunidade de consumidores foi proposta por Algesheimer, Dholakia e Herrmann (2005), que conceituaram o envolvimento da comunidade como uma "motivação intrínseca dos membros para interagir e cooperar com os membros da comunidade" (p. 21).

O engajamento do consumidor é impactado tanto pelo posicionamento em relação ao que a pessoa vivenciou, como também pelo posicionamento em relação aos fatos vivenciados por outras pessoas envolvidas (Gonçalves, 2009). Além disso, as interações aumentam o investimento e o envolvimento emocional, psicológico e físico que um consumidor tem por uma marca (Foreplay, 2011).

Sinha, Ahuja e Medury (2011) argumentam que, quando o conhecimento do consumidor sobre uma marca aumenta (através da mídia social), também aumenta o apego emocional à marca, independentemente do conteúdo das comunicações sociais da marca ser funcional ou emocional por natureza.

Segundo Rodrigues e Toaldo (2015), “o Relatório Anual de Engajamento Digital do Consumidor define engajamento como interações frequentes que fortalecem as relações emocionais, psicológicas ou físicas entre o consumidor e a marca" (p. 5).

Já o Instituto de Pesquisas Forrester Research (2015), dos Estados Unidos da América (EUA), entende que o engajamento está relacionado com o nível de determinados fatores, como o envolvimento, a interação, a intimidade e a influência que um indivíduo obtém com determinada marca ao longo do tempo.

Damacena e Marra (2012) afirmam que pesquisas sobre engajamento vêm crescendo cada vez mais em diversas áreas. Embora sujeito a várias interpretações, engajamento do consumidor é frequentemente entendido como um construto motivacional, com intensidade variada. Envolve um objeto (ou seja, uma marca) e um assunto (isto é, o consumidor), e tem uma valência (positiva versus negativa) (Brodie et al., 2011a; Hollebeek\& Chen, 2014).

Sheehan e Morrison (2009) apontam para a necessidade de criatividade no desenvolvimento de mensagens de marca que possam ser efetivamente entregues na mídia social e tradicional, ao mesmo tempo em que estimula o engajamento do consumidor a fim de produzir resultados de marca desejados.

As estratégias criativas podem aumentar a motivação, a oportunidade e/ou a capacidade do receptor de processar informações de um anúncio (Macinnis, Moorman\&Jaworski, 1991). Turchi (2012) acredita que "não basta apenas uma sacada criativa para o sucesso de uma campanha: planejamento e inteligência digital são fundamentais". (p. 70)

Pelo exposto, observa-se a relevância que a estratégia desenvolvida pelas empresas nas suas mídias sociais tem, uma vez que essas ferramentas propiciam que ocorra o engajamento do consumidor e, mais que isso, também a interação, para que ele se sinta parte da empresa e tenha uma integração de forma mais efetiva. 


\section{Metodologia}

Esta pesquisa caracterizou-se como exploratória e descritiva, de caráter qualitativo. A pesquisa exploratória se restringe à definição dos objetivos e a busca de maiores informações, neste caso, sobre o uso de mídias sociais por companhias aéreas. De acordo com Cervo et al.(2007) e Flick (2009), estudos de natureza exploratória objetivam a familiarização ou nova percepção de um certo fenômeno, podendo advir novas ideias ou formulações de ideias mais gerais. Na pesquisa descritiva estuda-se a relação entre o assunto abordado, a comunidade ou grupo em questão e a realidade pesquisada, onde é realizada a análise e descrição destes.

A estratégia de pesquisa adotada foi a de estudos de casos múltiplos, utilizando-se da observação on-line não participante que, segundo Ferreira et al. (2012), acontece em um cenário onde o pesquisador não está diretamente envolvido na situação analisada e não interage com o objeto da observação.

A observação on-line não participante foi realizada durante o período de três meses (março, abril e maio de 2018), no qual foram observados os conteúdos postados pelas empresas aéreas LATAM, GOL, AZUL e AVIANCA em suas páginas na rede social Facebook e a influência desses posts como ferramenta para o engajamento do consumidor.

Para análise do conteúdo on-line assumiu-se uma postura interpretativista, que segundo Mabrouki (2014) não se pode ter uma única representação da realidade, sendo esta representada pela observação do pesquisador na rede social Facebook.

Quanto à abordagem do problema norteador do estudo, a pesquisa caracteriza-se como qualitativa que, segundo Santos e Costa (2015) “[...] pode ser configurada em cenários presenciais ou on-line”. (p.59). A pesquisa quando realizada no cenário on-line permite a observação com mais afinco.

A coleta dos dados foi feita com a utilização da ferramenta LikeAlyzer, no período de março/ abril de 2018. Esta ferramenta já foi utilizada em estudos anteriores (Angelis, 2014; Afonso, 2014; Pires, 2017; Medeiros, 2016; França, 2017; Alcantara, 2018). A ferramenta LikeAlyzer, criada pela empresa Meltwater, permite a obtenção de valores das páginas no Facebook e o acesso a dados e a taxa de crescimento/decréscimo de utilizadores e seus níveis de interação. Outra vantagem da utilização desta ferramenta é que os dados obtidos reportam-se sempre a um espaço de 30 dias, o que torna possível ter uma ideia da forma de funcionamento da página e se a estratégia a ser usada apresenta bons resultados, sendo possível também obter recomendações para melhorias na página que está sendoanalisada, permitindo verificar se esta forma de comunicação está, ou não, sendo bem aproveitada.

\section{Resultados e análises}

\subsection{Dados Descritivos Ferramenta LikeAlyzer}

Segundo a ferramenta LikeAlyzer, o visual (foto/vídeo do perfil e capa) das páginas das empresas aéreas LATAM, GOL, AZUL e AVIANCA no Facebook oferecem para o visitante uma ótima primeira impressão, indicando uma percepção inicial positiva dos usuários sobre as páginas das empresas pesquisadas.

Outro aspecto avaliado por meio da ferramenta foi a quantidade de informações que as empresas disponibilizam na fanpage e, de forma complementar, o LikeRank ${ }^{\mathrm{TM}}$ (Pontuação da página no Facebook de $0 \%$ a $100 \%$ ), sendo estes dados representados na tabela 1.

\section{Tabela 1: Informações na Fanpage}

\begin{tabular}{|l|c|c|c|c|}
\hline LikeAlyzer & LATAM & GOL & AZUL & AVIANCA \\
\hline LikeRank $^{\mathbf{T M}}$ & $67 \%$ & $68 \%$ & $66 \%$ & $66 \%$ \\
\hline Sobre as empresas & $56 \%$ & $81 \%$ & $56 \%$ & $100 \%$ \\
\hline
\end{tabular}

Fonte: Elaborado pelos autores (2019)

Foram destacados itens como: marcos históricos, informações de contato e localização. Outro ponto avaliado foi a atividade, ou seja, como estas empresas estão utilizando esta rede social para se comunicar com o público. Sendo estes resultados demonstrados na tabela 2. 
Tabela 2: Atividade no Facebook

\begin{tabular}{|l|c|c|c|c|}
\hline LikeAlyzer & LATAM & GOL & AZUL & AVIANCA \\
\hline Atividade & $57 \%$ & $57 \%$ & $64 \%$ & $86 \%$ \\
\hline Fotos & $17 \%$ & $0 \%$ & $53 \%$ & $75 \%$ \\
\hline Notas & $75 \%$ & $0 \%$ & $6 \%$ & $0 \%$ \\
\hline Vídeos & $8 \%$ & $100 \%$ & $41 \%$ & $25 \%$ \\
\hline Posts por dia & 0.4 & 0.2 & 0.6 & 0.9 \\
\hline Eventos & 0 & 0 & 0 & 0 \\
\hline Vídeos nativos do Facebook & 13 & 25 & 25 & 25 \\
\hline Tamanho médio do post & 120 & 206 & 168 & 147 \\
\hline Páginas curtidas & 1 & 10 & 1 & 44 \\
\hline
\end{tabular}

Fonte: Elaborado pelos autores (2019)

Apenas a companhia aérea AVIANCA consegue manter o nível de atividade na rede social, as demais empresas aéreas, segundo indica a ferramenta LikeAlyzer (2018), deixam seus seguidores desejando mais. A pontuação sobre as fotos no Facebook é de $0 \%$ apenas para a companhia aérea GOL, as demais companhias aéreas apresentam índices baixos e medianos, respectivamente. Quando se avalia o item notas, a pontuação é satisfatória apenas para a LATAM. No que se refere aos vídeos, os postados pela GOL apresentam-se como extremamente satisfatórios.

Com relação à quantidade de posts diários, é evidenciado pela LikeAlyzer (2018) que uma página de Facebook deve otimizar o número de mensagens por dia para aumentar o engajamento do usuário, postar muito pouco ou demais pode prejudicar o engajamento. A AVIANCA possui a maior média de posts/dia e a GOL a menor média. É necessário que esta atividade no Facebook seja bem direcionada e consequentemente aproveitada.

Os vídeos nativos do Facebook representam valores iguais para as companhias aéreas GOL, AZUL e AVIANCA (25 vídeos/companhia aérea), apenas a LATAM possui um quantitativo inferior às demais (13 vídeos), e representam o tipo mais envolvente de conteúdo no Facebook. As páginas que os aproveitam provavelmente melhorarão o seu nível de engajamento total entre seus seguidores (LikeAlyzer, 2018).

O tamanho médio dos posts das empresas LATAM, AVIANCA, AZUL e GOL variam entre 120-206 caracteres. Segundo dados da pesquisa apresentados pela empresa Meltwater, responsável pela ferramenta LikeAlyzer, o tamanho do post é um item muito importante, no qual mensagens cujo tamanho varia entre 40-100 caracteres, em média, são responsáveis por mais engajamento entre os usuários. Caracteriza-se pelo envolvimento que o usuário possui com uma determinada fanpage, onde o envolvimento é a percepção de uma pessoa sobre a relevância do objeto em questão com base em necessidades, valores e interesses inerentes (Zaichkowsky, 1985, p. 342).

Curiosidade e diálogo entre páginas incentivam o interesse de domínio cruzado e melhora o engajamento geral (LikeAlyzer, 2018). Os usuários da rede social Facebook no momento em que decidem seguir determinada página, se sentem ansiosos por interagir com as mesmas, para isso é preciso que as companhias aéreas responsáveis por estas mídias sociais possuam agilidade em dar respostas para estes usuários, é aconselhado reduzir o tempo entre um post do usuário e a resposta da empresa. Uma taxa de resposta rápida indica uma marca que se importa com seus fãs/ seguidores (LikeAlyzer, 2018).

Os níveis de resposta das companhias aéreas LATAM, GOL e AZUL são classificados em 100\%, já na companhia aérea AVIANCA os usuários não podem postar e a capacidade de resposta da Fanpage desta empresa é de $0 \%$, o que prejudica a relação da empresa com os consumidores, pois permitir que os usuários postem em uma página é o primeiro passo para aumentar o engajamento (LikeAlyzer, 2018), já que a ausência de interações frequentes enfraquece as relações emocionais e psicológicas entre o consumidor e marca, algo fundamental para o engajamento (Rodrigues \& Toaldo, 2015).

Com relação ao engajamento em si dos usuários com as páginas das empresas, os resultados estão apresentados na tabela 3 . 


\section{Tabela 3: Engajamento}

\begin{tabular}{|l|l|l|l|l|}
\hline LikeAlyzer & LATAM & GOL & AZUL & AVIANCA \\
\hline Engajamento & $55 \%$ & $45 \%$ & $48 \%$ & $43 \%$ \\
\hline Pessoas falando sobre isso & 10.043 & 23.502 & 23.063 & 14.015 \\
\hline Total de Likes da Página & 11.285 .528 & 3.521 .677 & 4.185 .221 & 1.650 .467 \\
\hline
\end{tabular}

Fonte: Elaborado pelos autores (2019)

Observa-se que o engajamento das empresas com os usuários é bem próximo, tendo a LATAM o melhor resultado, mas não tão distante das outas três empresas e, como pode ser observado, as companhias aéreas podem melhorar nesse quesito. A quantidade de pessoas falando sobre isso é medida por meio da qual observa-se o quantitativo de pessoas que interagiram com a página ou com o conteúdo, de qualquer maneira, nos últimos sete dias. Já no que se refere ao total de Likes na Página, quanto maior melhor, quanto mais seguidores atuais a página adquire mais alcance terá. Segundo Chu e Kim (2011), o número de fãs que essas páginas apresentam é considerado um dos mais fortes indicadores do poder da marca da empresa.

\subsection{Observação on-line não participante}

Como método maior de aprofundamento foi investigado na rede social Facebook publicações que apresentassem um contexto maior de envolvimento dos usuários nas fanpages da LATAM, GOL, AZUL e AVIANCA. As publicações analisadas foram dos meses de março, abril e maio de 2018, somando o total de 28 publicações da companhia aérea LATAM, 21 publicações da companhia aérea GOL, 52 publicações da companhia aérea AZUL e 65 publicações da companhia aérea AVIANCA. Foram analisados itens como: total de reações, comentários e compartilhamentos de cada publicação destes meses citados. Sendo apresentado na tabela 4 o quantitativo de reações de cada publicação, a qual representou um maior nível de envolvimento com os usuários desta rede social.

Souza (2016) descreve as possibilidades de reações que os usuários podem ter às postagens no Facebook e o que elas podem significar. O Like não expressa nenhuma forte reação ou mudança de humor em relação a alguma publicação no perfil de um amigo ou página de marcas. Também é a opção mais "preguiçosa", já que um simples clique no botão conta como curtida no post. O Like também pode ser usado para demonstrar aprovação de um argumento, notícia ou foto no seu feed, embora não tão forte quanto o Amei. A ideia por trás desse botão do Facebook é demonstrar forte aprovação a uma atualização publicada na rede. O Haha é voltado para conteúdos engraçados, substituindo até mesmo os antigos comentários de risos. Há quem o use para ser irônico/sarcástico ou demonstrar um pouco mais de simpatia que o simples Curti. O Uau é o novo botão ideal para quando algo lhe surpreende no Facebook. O Sad também pode ser usado como forma de desaprovação. O Grr é a reação que pode ser usada para demonstrar raiva ou total desaprovação com o conteúdo publicado nesta rede social.

Tabela 4: Total de reações na postagem

\begin{tabular}{|l|l|}
\hline LATAM & 29.190 \\
\hline GOL & 18.714 \\
\hline AZUL & 60.762 \\
\hline AVIANCA & 11.000 \\
\hline
\end{tabular}

Fonte: Elaborado pelos autores (2019)

A postagem da empresa aérea LATAM nesta rede social foi publicada às $10 \mathrm{~h}$, no dia 18 de Abril de 2018 (quarta-feira). Uma divulgação sobre a LATAM Cargo (serviço de transporte de cargas), tendo como mensagem o texto "sua encomenda de norte a sul no mesmo dia" junto a uma imagem que retrata as regiões e a entrega de uma encomenda. O dia e horário também são requisitos para um maior alcance de público, o quantitativo de reações na postagem desta companhia dividiu-se em 29 mil likes, 121 
reações do tipo love, 38 do tipo haha, 17 do tipo wow, 2 do tipo sad e 12 do tipo angry. Para Perinoto (2013), pode-se reafirmar que a imagem é um item de grande relevância para a quantidade de reações, o que pôde ser verificado nessa postagem.

A empresa aérea GOL teve o menor número de publicações entre os meses observados (março, abril e maio). A postagem que gerou o maior quantitativo de reações foi em formato de vídeo, sendo este publicado às 19h28min, no dia 20 de Março de 2018, alcançando o total de 926 mil visualizações, tendo como legenda de publicação: "Para buscar a sexta estrela a gente vai até o céu! Confira a nova pintura da aeronave Canarinho, pronta para decolar rumo ao Hexa! GOL. Transportadora Oficial da Seleção e dos Brasileiros. \#VoaCanarinho \#VoeGOL”. O quantitativo de reações nesta postagem dividiu-se em 17 mil likes, 1 mil love, 62 haha, 617 wow, 5 sad e 30 angry.

A postagem da empresa aérea AZUL no Facebook gerou o maior número de reações em comparativo com as demais fanpages (LATAM, GOL e AVIANCA), a mesma procura interagir com os usuários desta rede social por meio de uma pergunta em complemento à imagem postada, um dos itens essenciais na busca pelo engajamento. Postagens que contêm citações, perguntas, dicas, solicitação de participação do usuário em perguntas convidativas, postagens diferentes na fanpage, memes, temas em alta, imagens, vídeos, "concursos" (do tipo "marque um amigo"), chamadas para ação (do tipo "comente aqui" ou "clique no link para saber mais"), trivias (podendo utilizar-se também das hashtags para maior engajamento do usuário), links, posts compartilhados por outras páginas do Facebook, Storytelling possuem melhor engajamento quando postadas em formato de vídeo). A postagem foi realizada no dia 7 de Maio de 2018, sendo publicada em período noturno do início da semana, onde as reações dividiram-se em 55 mil likes, 4,4 mil love, 46 haha, 1,3 mil wow, 10 sad e 6 angry. Segundo Gastal (2005) quando se relaciona marketing digital e turismo, a imagem é extremamente relevante para este alcance de público.

A AVIANCA, por meio de sua rede social Facebook, fez uma publicação em homenagem ao Dia Internacional da Mulher (08 de março), porém a mesma recebeu diversos comentários de insatisfação para com a publicação e para com a didática da empresa em certos acontecimentos, tendo esta o menor índice de engajamento em comparativo com as demais companhias aéreas (LATAM, GOL e AZUL). O fato de ter feito uma publicação em homenagem ao Dia Internacional da Mulher e neste dia a empresa ter realizado um voo com a tripulação apenas do sexo feminino gerou revolta entre seus usuários. A postagem contém duas fotos, cada uma possui o total de 118 e 182 reações, respectivamente. Já a publicação totaliza 11 mil reações, onde 1,8 mil demonstra sentir-se zangada com a publicação.

Os comentários analisados foram ditos os mais relevantes, que são os comentários de amigos e de pessoas com mais visualizações, reações, respostas e outros que aparecem no topo. O quantitativo de compartilhamentos demonstra o quanto este usuário está envolvido com a postagem. Na tabela 5 está representado o número total de comentários e compartilhamentos das quatro postagens que tiveram o maior nível de engajamento.

\section{Tabela 5: Comentários e Compartilhamentos na publicação}

\begin{tabular}{|l|c|c|}
\hline Empresa & Comentários & Compartilhamentos \\
\hline LATAM & 107 & 141 \\
\hline GOL & 935 & $3,1(\mathrm{mil})$ \\
\hline AZUL & $1,6(\mathrm{mil})$ & $2,405(\mathrm{mil})$ \\
\hline AVIANCA & $1,4(\mathrm{mil})$ & 264 \\
\hline
\end{tabular}

Fonte: Elaborado pelos autores (2019)

Todos os comentários ditos relevantes contêm diversos tipos de reclamações para com a empresa LATAM, sobre vários tipos de serviços prestados pela empresa. O comentário do topo possui o maior número de reações (likes) que os comentários dos demais usuários, o comentário foi feito dois dias após a postagem no período da tarde. A LATAM respondeu a este usuário no mesmo dia do comentário já em período noturno, o feedback foi reportado 13 dias após o último comentário da LATAM, sendo ele, segundo a reclamação, satisfatório.

A empresa aérea GOL teve o maior número de compartilhamentos em comparativo com as demais empresas aéreas (LATAM, AZUL e AVIANCA). Os comentários na postagem desta companhia aérea 
dividiram-se em elogios, algumas reclamações e sugestões. O comentário do topo possui 40 reações, divididas em 33 likes, 2 love e 5 haha. A partir deste comentário surgem 35 respostas, onde a GOL se pronuncia 6 vezes, os usuários criaram um certo "bate-papo" neste comentário do topo, o qual teve fim 36 dias após a postagem da GOL, onde este comentário inicial do tipo relevante fez alusão à legenda de publicação da empresa aérea GOL, fazendo também uma reclamação referente ao serviço de bordo (WI-FI) e o lanche servido nos voos desta empresa aérea, a partir desse momento o usuário também ironiza a publicação da GOL através de seu comentário, enaltecendo o valor/importância do cliente GOL para a Companhia Aérea. As respostas que surgem a seguir se apoiam neste comentário inicial contando também seus relatos, em acordo ou desacordo com este.

A publicação da AZUL teve o maior número de comentários entre as fanpages observadas (LATAM, GOL e AVIANCA). A empresa foi a única que teve como resultado da análise de publicações na fanpage, do item comentários mais relevantes, o comentário do topo com destaque para elogio. O usuário reage com um comentário feliz e recebe 48 tipos de reações, gerando novos comentários/respostas (25 respostas), os usuários formam um tipo de "bate-papo" neste comentário do topo onde discutem sobre suas profissões, questões financeiras e a capacidade/planejamento de viajar para Paris (foto em destaque), a cada nova resposta neste comentário inicial surgem novas reações, demonstrando envolvimento com a publicação. Os demais comentários do tipo relevantes possuem elogios, relatos e algumas reclamações. Apenas um único usuário respondeu uniformemente ao conteúdo/pergunta postado pela AZUL na rede social Facebook, o usuário marcou outros 5 amigos na postagem "dizendo levá-las para Paris em seu aniversário", é importante ressaltar que o usuário ao marcar outros usuários em uma postagem, faz com que o público para essa publicação também aumente, atingindo um maior alcance de postagem, este fato corrobora com os argumentos de Falls (2010).

A publicação da AVIANCA gerou revolta entre seus usuários onde os comentários expõem casos de assédio em voos, entre outros assuntos, que segundo estes usuários foram "vedados" pela empresa aérea. O comentário inicial possui 199 reações (valor maior que as reações nas duas fotos da publicação), deste comentário inicial surgem 22 respostas, a AVIANCA se pronuncia no dia seguinte ao comentário, porém não satisfaz aos anseios de seus usuários, logo as respostas se estendem até o dia 14 de Março. Apenas uma pequena parcela de usuários faz comentários parabenizando a empresa. A resposta da companhia aérea AVIANCA ao comentário inicial obteve 76 reações, onde 49 usuários responderam com tonalidade raivosa, a mensagem dizia: "Oi, Jacky! Na verdade, o que fizemos de diferente neste dia foi apenas acompanhar o voo desta tripulação. Não é incomum que esse tipo de escala exista aqui na Avianca Brasil. :)".

\section{Considerações finais}

O engajamento do consumidor on-line com as empresas aéreas LATAM, GOL, AZUL e AVIANCA revela-se por meio das interações de seus usuários em suas fanpages. Estas interações ocorrem por meio dos comentários deixados no post, pelas reações e ele, pelos compartilhamentos, pelas curtidas na página, pelas opiniões sobre cada empresa aérea e pelos elegios, críticas e sugestões. A audiência do cliente pode ser vista como uma medida da qualidade de uma relação entre o cliente e uma empresa (De Wulf \& Odekerken-Schro“Der, 2001).

A fanpage da companhia aérea LATAM caracteriza-se por não curtir e interagir com as demais páginas do Facebook. As companhias aéreas GOL e AZUL se mostram atenciosas com os seus internautas nesta rede social, a AVIANCA possui conteúdos que chamam a atenção, porém os seguidores não podem postar conteúdo nesta página, o que dificulta o engajamento destes usuários. São pontos semelhantes entre essas empresas: a quantidade de conteúdo postado e a falta de eventos no Facebook, porém estas empresas levam vantagem quando se faz referência ao tamanho do post, pois demonstram prezar pela qualidade do mesmo, resultando no excelente engajamento, corroborando com a argumentação de Sheehan e Morrison (2009).

A análise realizada possibilitou observar que há pontos a serem melhorados, onde beneficiam-se tanto os usuários quanto as respectivas empresas aéreas, ao abordar suas carências enquanto fanpages e sua influência na qualidade e prestação do serviço, apontando suas fraquezas à medida que avalia suas referências de engajamento. Estas empresas têm potencial para melhorarem suas ações e postagens nesta rede social, tendo como resultado a otimização da prestação de serviço ao consumidor favorecendo o engajamento on-line. 
Este estudo sobre as companhias aéreas brasileiras e suas mídias sociais, neste caso (o Facebook) se torna de grande valia para futuras pesquisas sobre engajamento do consumidor on-line e serviços turísticos, em específico, o serviço de transporte aéreo, uma vez que dispõe de grande quantidade de informações sobre estes, sendo recomendado para futuras pesquisas a exploração também de outras mídias sociais, como o Twitter e o Instagram destas empresas.

\section{Bibliografía}

Afonso, C. (2014). A utilização de plataformas de social media pelos museus. Lisboa: ISCTE-IUL, 2014. (Dissertação de mestrado). Recuperado de:http://hdl.handle.net/10071/9446

Alcantara, J. (2018). Distribuição de conteúdo nas redes sociais, desafios a serem vencidos e estratégias para enfrentá-los. Ano XIV, n. 05. maio/2018. NAMID/UFPB - Recuperado de: http://periodicos. ufpb.br/ojs2/index.php/tematica

Algesheimer, R. \& Dholakia, U. M. \& Herrmann, A. (2005). The social influence of brand community: evidence from European car clubs, Journal of Marketing, Vol. 69 No. 3, pp. 19-34.

Angelis, F. (2014). Governança em tempos de redes sociais e as manifestações de junho de 2013 no Brasil. Democracia Digital e Governo Eletrônico, Florianópolis, $n^{\circ} 11, p$. 264-294.

Balanço 2017 (2018). Recuperado de http://transportes.gov.br/ultimas-noticias/6769-setor-a\%C3\%A9reo-registra-crescimento-de- $2 \% 2 \mathrm{C} 33$-na-movimenta $\% \mathrm{C} 3 \% \mathrm{~A} 7 \% \mathrm{C} 3 \% \mathrm{~A} 30$-de-passageiros-e-10\%2C 47 -nas-cargas.html

Baldan, A. K., Eras, A. L., Fedichina, M. A. H. \& Gozzi, S. (2011). A Estratégia de Relacionamento com o Cliente por meio das Redes Sociais. Anais do XIV Seminários em Administração, São Paulo, SP, Brasil.

Basfirinci, C. \& Mitra, A. (2015). A cross cultural investigation of airlines service quality through integration of Servqual and the Kano model. Journal of Air Transport Management, v. 42, p. 239-248.

Brodie, J. R., Hollebeek, L., Juric, B. \& Ilic, A. (2011). Consumer engagement: conceptual domain, fundamental propositions and implications for research, Journal of Service Research, Vol. 14 No. 3, pp. 252-271.

Cavallini, R. (2008). O marketing depois de amanhã: explorando novas tecnologias para revolucionar a comunicação. 2 ed. São Paulo.

Cervo, A. et al. (2007). Metodologia científica. 6. ed. São Paulo: Pearson Prentice Hall.

Chu, S. C. \& Kim, Y. (2011). Determinants of consumer engagement in electronic word-of-mouth (eWOM) in social networking sites. International journal of Advertising, v. 30, n. 1, p. 47-75.

Damacena, C. \& Marra, G. S. (2012). Engajamento do consumidor: revisão teórica do conceito e seus antecedentes. São Paulo. Recuperado de: <http://www.regeusp.com.br/arquivos/2013.2.6.pdf>

De Wulf, K. \& Odekerken-Schro"der, G. (2001). A critical review of theories underlying relationship marketing in the context of explaining consumer relationships, Journal for the Theory of Social Behaviour, Vol. 31 No. 1, pp. 73-102.

Falls, J. (2010). What is engagement and how do we measure it? Social Media Explorer. Recuperado de http://www.socialmediaexplorer.com/2010/01/04/what-isengagement-and-how-to-we-measure-it.

Fernandes, R. (2019). Saiba quais foram os 10 aplicativos mais baixados no mundo. Redes sociais como Facebook, Whatsapp, Instagram e o fenômeno Tik Tok estão na lista. Recuperado de https://www. techtudo.com.br/noticias/2019/01/saiba-quais-foram-os-10-aplicativos-mais-baixados-de-2018-no-mundo.ghtml

Ferreira, L. B., Torrecilha, N. \& Machado, S. H. S. (2012). A técnica de observação em estudos de administração. XXXVI Encontro da ANPAD. Rio de Janeiro/ RJ - 22 a 26 de setembro.

Flick, U. (2009). Uma introdução à pesquisa qualitativa. Porto Alegre: Bookman.

Foreplay. (2011). Relatório mundial de engajamento digital do consumidor 2011: dados, insights e tendências. 2011. Recuperado de http://www.foreplay.com.br/engajamento_digital_2011.pdf.

Forrester (2015). Forrester. Recuperado de https://go.forrester.com/blogs/14-04-29-instagram_is_the_ king_of_social_engagement/.

França, M. N. \& Carvalho, A. M. G. (2017). Monitoramento de mídias sociais: um estudo exploratório em bibliotecas universitárias públicas federais. XVIII Encontro Nacional de Pesquisa em Ciência da Informação - ENANCIB 2017. 23 a 27 de outubro de 2017 - Marília - SP.

Gastal, S. (2005). Turismo, imagens e imaginários. São Paulo: Aleph.

Gonçalves, P. (2009). Modalidade e engajamento em editoriais de imprensa paulistana de bairro. In: Congresso Nacional de Linguística e Filosofia. Anais. Rio de Janeiro: CiFEFIL, 2009. 2115-2127. 
Hollebeek, 1. \& Chen T. (2014). Exploring positively-versus negatively-valenced brand engagement: a conceptual model, Journal of Product \& Brand Management, Vol. 23 No. 1, pp. 62-74.

Hussain, R., Nasser, A. A. \& Hussain, Y. K. (2015). Service quality and customer satisfaction of a UAE-based airline: an empirical investigation. Journal of Air Transport Management, v. 42, p. 167-175.

Jang, S. (2004). The past, present, and future researchof on-line information search. JournalofTravel \& Tourism Marketing, 17(2/3), 41-47.

Lacerda, D.R.A. (2018). Busca por informação no processo decisório dos consumidores: uma interação entre usuários e influenciadores de moda nas midias sociais. Trabalho de Conclusão de Curso, Graduação em Administração, Universidade de Brasília, Brasília, Brasil.

Lemos, A.\& Levy, P. (2010). O Futuro da Internet: Em Direção a uma Ciberdemocracia Planetária . (1st ed.). São Paulo: Paulus Editora.

Likealyzer (2018). Likealyzer. Recuperado de: https://www.meltwater.com/likealyzer-sunset.

Mabrouki, N. (2014). Méthodologie de recherche: regardépistémologique. Recuperado de: <http://economia. $\mathrm{ma} / \mathrm{fr} / \mathrm{bg} /$ nabil-el-mabrouki/methodologie-de-recherche-regard-epistemologique-1>. 2014.

Macinnis, D., Moorman, C. \& Jaworski, B. (1991). Enhancing and measuring consumers'motivation, opportunity and ability to process brand information. Journal of Marketing, 55, 32-53.

Medeiros, D. \& Lucas, E. R. O. (2016). As bibliotecas nacionais latino-americanas e o capital social. Perspect. ciênc. inf., Belo Horizonte, v. 21, n. 4, p. 202-224.

Menezes, V. O. \& Cunha, S. K. (2013). Inovação como instrumento de desenvolvimento da atividade turística. Observatório de Inovação do Turismo Revista Acadêmica.

Mihajlovic, I. (2012). The Impact of Information and Communication Technology (ICT) as a Key Factor of Tourism Development on the Role of Croatian Travel. Agencies International Journal of Business and Social Science. Vol. 3, No. 24

Ogden, J. \& Criscitelli, E. (2007). Comunicação Integrada de Marketing: modelo prático para um plano criativo e inovador. São Paulo: Prentice Hall.

Oliveira, A, Durão, A \& Silveira, C. (2017). Marketing Digital e a Rede Social Facebook nos Serviços Turísticos: uma investigação sobre a interação entre os consumidores finais e a companhia aérea LATAM. Id on Line Multidisciplinary and Psycology Journal, 11(37), 178-195. https://doi.org/10.14295/ idonline.v11i37.820.

Organização Mundial do Turismo (OMT) (2013). E-business para o turismo. Porto Alegre: Bookman, 2013.

O'Reilly, T. (2007). What is Web 2.0: Design Patterns and Business Models for the Next Generation of Software. Communications \& Strategies, 1(First Quarter), 17. https://doi.org/10.2139/ssrn.1008839

Perinotto, A. R. C., 2013. Investigando a comunicação turística de Parnaíba/PIBrasil: Internet e redes sociais, descrição e análise. Turydes: revista de investigación en turismo y desarrollo local, v. 6, n. 15.

Pires, O. (2017). Avaliando a utilização do Facebook como ferramenta de marketing para novos empreendimentos na área de tecnologia da informação. 91 páginas. Trabalho de Conclusão de Curso (graduação) - Universidade Federal do Ceará, Campus de Quixadá, Curso de Redes de Computadores, Quixadá.

PricewaterhouseCoopers. (n.d.). Global Consumer Insights Survey 2018. Recuperado de: https://www. pwc.com.br/pt/setores-atividade/varejo-consumo/gcis2018.html.

Primo, A.(2007). O aspecto relacional das interações na Web 2.0. Recuperado de: <http://www.moodle. ufba.br/file.php/10203/cultura_digital/web2_primo.pdf>.

Reino, L. S. A. (2012). Redes Sociais e Marketing Digital, o Caso do Firula's Café. Recuperado em 30 de setembro de 2019 de http: / /www.bocc.ubi.pt/.

Rodrigues, A. I. \& Toaldo, M. M. (2015). Interação e engajamento entre marcas e consumidores / usuários no Facebook. Recuperado de: <http://portalintercom.org.br/anais/nacional2015/resumos/R10-3205-1.pdf>.

Santiago, A. (2009). O uso corporativo da Web 2.0 e seus efeitos no relacionamento com o consumidor. Recuperado de: http://www.bookess.com/read/3110-o-uso-corporativoda-web-20-e-seus-efeitos-no-relacionamento-com-o-consumidor/.

Santos, V. L. P. \& Costa, C. J. S. A. (2015). A observação on-line como instrumento investigativo: uma experiência utilizando fórum de discussão. Debates em Educação - ISSN 2175-6600. Maceió, Vol. 7 , n. 15, Jul./Dez. 2015.

Sheehan, K. \& Morrison, D. (2009). The creativity challenge: media confluence and its effects on the evolving advertising industry. Journal of Interactive Advertising, 9, 40-43.

Silva, A. P.; Pereira, F. A.; Correia-Neto, J. S. (2013). Engajamento digital: um estudo com páginas de instituições de ensino superior no Facebook. Revista Brasileira de Administração Científica, 4(2), 140-157. http://dx.doi.org/10.6008/ESS2179_684X.2013.002.001므 
Sinha, N., Ahuja, V. \& Medury, Y. (2011). Corporate blogs and internet marketing-using consumer knowledge and emotion as strategic variables to develop consumer engagement. Journal of Database Marketing and Customer Strategy Management, 18, 185-199.

Souza, E. (2016). Entenda os significados dos botões do Facebook Reactions.Techtudo, 2016. Recuperado de: $<$ <ttp://www.techtudo.com.br/dicas-e-tutoriais/noticia/2016/02/grr-uau-haha-entenda-significados-dos-botoes-do-facebook-reactions.html>.

Suzart, J. A. \& Dias Filho, J. M. (2009). A web 2.0 e os programas brasileiros de pós-graduação em Contabilidade. In: Encontro da ANPAD, 33. 2009, São Paulo. Anais eletrônicos. São Paulo: Associação Nacional de Pós-Graduação e Pesquisa em Administração. Recuperado de :<http://www.anpad.org. br/download_pdf.php?cod_edicao_trabalho=10636\&cod_evento_edicao=45>.

Terra, C. (2010). Usuário-mídia: a relação entre a comunicação organizacional e o conteúdo gerado pelo internauta nas mídias sociais. 2010. 217 p. (Tese deDoutorado) - Universidade de São Paulo, São Paulo.

Turchi, S. (2012). Estratégias de marketing digital e-commerce. São Paulo: Atlas, 2012.

We Are Social (2019). Global Digital Report 2019: essential insights into internet, social media,mobile, andecommerce use aroundthe world [Blog]. Recuperado de: https://digitalreport.wearesocial.com/

Yadav, M.S. \& Pavlou, P.A. (2014). Marketing in Computer-Mediated Environments: research synthesis and new directions. Journal of Marketing. Vol. 78, n.1. https://doi.org/10.1509/jm.12.0020

Zaichkowsky, J. (1985). Measuring the involvement construct. Journal of Consumer Research, 12, 341-352. https://doi.org/10.1086/208520

\section{Notas}

1 Realização da análise dos dados com a ferramenta LikeAlyzer no dia 27 de abril de 2018. 